\title{
Effectiveness of a sex education program for mothers of adolescent girls based on Health Belief Model on mothers' knowledge, attitude, and behaviour
}

\author{
Nahid Mostofi ${ }^{1}$, Ahmad R Shamshiri ${ }^{2}$, Elham Shakibazadeh ${ }^{1}$ and Gholamreza Garmaroudi ${ }^{2 *}$ \\ ${ }^{1}$ Department of Health Promotion and Education, School of Public Health, Tehran University of Medical Sciences, Poursina Ave, Ghods Ave, Keshavarz Blvd, \\ Tehran, Iran \\ ${ }^{2}$ Department of Epidemiology and Biostatistics, School of Public Health, Tehran University of Medical Sciences, Poursina Ave, Ghods Ave, Keshavarz Blvd, \\ Tehran, Iran
}

\begin{abstract}
Background: Despite importance of sexual education for youngsters, no standard and culture-based sex education protocol is available in Iran. We designed a brief intervention using the Health Belief Model on improving sexual education delivered by mothers to adolescent girls. This study aimed to assess the effectiveness of this intervention on mothers' knowledge, attitude, and behaviour.

Methods: In this randomized controlled trial, we recruited 60 mothers of adolescent girls to the study during three months in 2015 in Tehran, Iran. The inclusion criteria were being literate and having a teenage girl aged 10-19 years old. After baseline measurement, we randomly allocated mothers into two intervention ( $\mathrm{n}=30$ ) and control $(n=30)$ groups. Mothers in the intervention group attended three-session educational classes over 3-week period each lasted 45-60 minutes. Validated questionnaires assessed study outcomes at baseline and three months after the intervention. The CONSORT statement was adhered to where possible. Data were analyzed using the Chi-squared test, Fisher's exact test, independent T-test and one-way ANOVA.
\end{abstract}

Results: A total of 60 individuals (100\%) attended the program. By three months, the intervention group showed significant improvements in the knowledge, attitude, behaviour, perceived susceptibility and perceived barriers $(P<0.001)$. These improvements were not seen in the control group during the study $(P>0.05)$.

Conclusion: Our educational intervention was effective in improving knowledge, attitude, behaviour, and some Health Belief Model constructs among mothers. Given the large number of adolescent girls in Iran, cultural sensitivities, and lack of standard sexual education, this intervention deserves consideration for implementation.

\section{Introduction}

Adolescence is a period of human development that occurs after childhood and before adulthood, ranging 10-19 years old [1]. The world's population is currently over 7 billion [2]; and approximately one out of every six people in the world are adolescence with a population of 1.2 billion [3]. In 2016, the population of Iran was about 79 million and $7.12 \%$ were adolescents aged 10 to 14 years old and $6.83 \%$ were people aged 15-19 years [4].

The adolescence period of life places them in tense situations. The most common problems in this age range include: physical problems; academic failure; difficulty in communicating with family members, peers and relatives; emerging high-risk behaviours; high prevalence of sexually transmitted diseases and HIV; mental problems; infectious diseases; unsuccessful marriages; early pregnancies; unsafe abortions; increasing sexual activity and unprotected sex; sexual violence; malnutrition and alcohol and drug use [3,5-8].

A large part of the problems that teens are facing with during this period is due to their exposure to puberty. Sexual maturity begins with gonadal activity through which a series of physical and psychological changes occur. This is coincided with the time that teens are getting acquainted with sex. Familiarity with the emerging sexual phenomena and the correct way of coping with them is one of the most basic needs of adolescents at this stage of life [9].
Maternal complications are the second leading causes of death among girls between the ages 15 to $19 ; 11 \%$ of all births is done by girls aged 15 to 19 , with a vast majority in low- and middle-income countries (LMICs). Pregnancy at early ages, although slowing down, still accounts for 15 million out of 135 million live births in the world among women aged 15-19 years. Adolescent girls and young women ages (15-24) are exposed to HIV twice more than young men, which is more related to unsafe, unwanted and compulsive sexual activity $[10,11]$.

Because of the exploration nature of teenagers and trying to be independent from family, the issues and concerns of adolescents in the physical, psychological and social fields are often unknown or unmet properly [12]. Occasionally, inaccurate or incomplete information from other sources like peers cause physical and psychological problems. Also, many teens do not look for help while having a serious health

*Correspondence to: Gholamerza Garmaroudi, Department of Health Education and Promotion, School of Public Health, Tehran University of Medical Sciences, Poursina Ave, Ghods Ave, Keshavarz Blvd, Tehran, Iran, E-mail: garmaroudi@tums.ac.ir

Key words: knowledge, attitude, brief intervention, sexual education, adolescent, mothers, health belief model

Received: December 17, 2018; Accepted: December 27, 2018; Published: December 31, 2018 
concern especially about sexual issue [13-15]. Studies have shown that hiding girls' sexual problems, lack of positive interaction between mothers and girls due to embarrassment, negative attitudes, fear of girls' disgrace and lacking enough information are other cultural issues that can hinder a safe sex education to girls [16-18].

Sexual conversation is often one of the most challenging conversations between families and their teens. Many studies have shown that the relationship between adolescents-parents about sex can greatly reduce the risk of juvenile sexual problems. However, many families, because of uncertainty or lack of confidence, negative attitudes and unwillingness to talk about sex with adolescents, avoid giving the best information to their children about sexual health or communications. Additionally, familial communication about sexual issues is not well-known for teens [19].

Although many families acknowledge the need to inform and express guidance on STDs and AIDS, they are not very confident if they can talk to their children about sexual issues [20].

In spite of the communication barriers between parents and adolescents for sexual education, it should be noticed that parents are the first, most important and most accessible people to educate adolescents [21]. Increasing parents' awareness and making the belief that they can address many of their teenage children problems, especially their sexual needs can help promoting adolescents' sexual health promotion [22].

The Health Belief Model (HBM) is one of the first health behaviour change models which have been developed solely for health behaviours [23]. This model emphasizes how individual perceptions and beliefs about fear of a health problem and the assessment of the benefits and barriers of preventive behaviours cause doing a behaviour [24]. According to the HBM, in order to take preventive actions, individuals at first feel danger in facing with the problem; then they perceive the depth of risk and its seriousness, and if there is a positive evaluation of the benefits of preventive behaviour and there is no serious barriers, they adopt healthy behaviours. The main structures of the model include susceptibility, strength, perceived benefits and barriers and a guide for action and self-efficacy [23].

The aim of this study was to assess the effectiveness of a sex education program for mothers of adolescent girls based on the HBM on mothers' knowledge, attitude, and behaviour.

\section{Methods}

This was a randomized controlled trial. Permission to conduct the current study was granted by the research deputy of the Tehran University of Medical Sciences. This trial was registered in the Iranian Registry of Clinical Trials (IRCT IRCT2015102824750N2). The CONSORT statement was adhered to where possible.

\section{Setting}

We conducted our study in two military settlements (Namjoo and Golestan) located in Tehran (district number 11) with a total population of 2,000 people and similar socioeconomic status.

\section{Sample}

The study team extended a telephone invitation to mothers living in Namjoo and Golestan settlements that had 10-19-year-old daughters. Due to the limited number of populations, we recruited all the mothers living in the area. The participants were informed of the study and its aims over the phone. Participants who met the inclusion criteria (being literate and having a teenage girl aged 19-10 years) were invited to the trial $(\mathrm{n}=30)$. The researcher-structured questionnaire was used to measure knowledge, attitude, behaviour, and the HBM constructs at baseline. The locations were randomly assigned into two intervention (Namjoo) and control (Golestan) groups (30 participants in each group). For this purpose, NM provided a list of eligible participants, gave them numbers, and randomized them using the random number generator.

In order to calculate the sample size for this study, we used the followings: to show at least $20 \%$ difference between the mothers' behaviour (dependent variable) between the two groups at $95 \%$ confidence level and $80 \%$ statistical power with a standard deviation of 25 units (1.4 possible score range of the variable), the minimum sample size required in each group was 25 , accounting for $20 \%$ attrition rate, the final sample size was considered 30 mothers in each group.

\section{Intervention}

The intervention was designed based on the HBM, tailored to the Iranian mothers, using expert panel. Group sessions were held once a week for 3 weeks. Each session lasted about 45-60 minutes and a pamphlet was delivered to the participants. The active learning intervention sessions were covered with certain topics including: Adolescence, Menstrual health, Sexual health, Pregnancy, etc. The sessions were held by an expertise public health educator (NM) providing question and answer time, lecture, face to face and group discussions. A pamphlet was delivered to the participants of the control group.

To minimize the likelihood of differential intervention or assessments of outcomes, interventionists, data collector, and data analysts were blind in the trial.

\section{Measures}

Data were collected using a researcher-structured questionnaire. The questionnaire consisted of demographic characteristics (14 items), Knowledge ( 10 items), attitude (10 items), behaviour ( 6 items), and the HBM constructs. The knowledge items were scored 1 for the correct answers and zero for the wrong and "I do not know" answers. Attitude items were scored based on Likert 5-point scale (totally agree, agree, no idea, disagree, and totally disagree) from 5 to 1 point so that the highest score was 50 and the lowest score was 10 . The behavior items were scored 2 for Yes answers, 0 to No answers and 1 to "somewhat" answers. Thus, the highest score was 12 and the lowest score was 0 . The HBM construct items included: perceived susceptibility (5 items), perceived severity (6 items), perceived benefits ( 5 items), perceived barriers ( 5 items), self-efficacy (5 items) and cues to action (5 items), which were based on Likert 5-point scale from 5 to 1 .

The content of the questionnaire was confirmed using expert opinion. We used the test-retest method for reliability testing. The correlation coefficients were as follow: knowledge (83.4), attitude (77.5), performance (70.6), perceived barriers (85.3), perceived benefits (83.2), perceived sensitivity (75), perceived severity (74.2), cues to action (85.5), self-efficacy (70.5) and for the whole questionnaire (74.4).

\section{Ethical considerations}

Tehran University of Medical Sciences' ethics committee approved aims and procedures of this study (TUMS IR.TUMS.REC.1394.963). All participants were informed about the study and purposes and were ensured that all information collected will remain confidential. Every participant signed an informed consent form. 
Mostofi N (2018) Effectiveness of a sex education program for mothers of adolescent girls based on Health Belief Model on mothers' knowledge, attitude, and behaviour

\section{Data analysis}

Frequency distributions, means, and standard deviations were calculated to describe the sample. A two-sided significance level of $5 \%$ was used for statistical inferences. The Chi-squared test and independent sample $t$ test were used to assess comparability of groups at baseline. The Chi-squared, Fisher's exact tests, independent t-test and one-way ANOVA were used to test the hypothesis.

\section{Results}

\section{Sample characteristics and group comparisons at baseline and after the intervention}

From the total number of mothers of adolescent girls living in Namjoo and Golestan settlements $(\mathrm{n}=100), 60$ individuals were eligible and agreed to participate in the study. Baseline measurements were carried out for all 60 participants. All participants who were recruited remained in the study till the last measurement at 3 weeks.

The mean ages of the participants at recruitment were $43(\mathrm{SD}=5)$ and $40(\mathrm{SD}=5)$ for the intervention and control groups, respectively. The characteristics of the participants and outcome measures of participants at baseline in both groups were presented in the table 1. No significant differences were found between the intervention and control groups for demographic or outcome variables at baseline.

\section{Study outcomes}

Table 2 shows differences of outcome measures between the intervention and control groups. While the mean knowledge scores in

Table 1. Demographic characteristics of participating households

\begin{tabular}{|c|c|c|c|c|c|}
\hline & & \multicolumn{2}{|c|}{$\begin{array}{c}\text { Comparison } \\
\text { group } \\
\mathbf{N}=\mathbf{3 0}\end{array}$} & \multicolumn{2}{|c|}{$\begin{array}{c}\text { Intervention } \\
\text { group } \\
\mathbf{N}=\mathbf{3 0}\end{array}$} \\
\hline & & $\mathbf{N}$ & $\%$ & $\mathbf{N}$ & $\%$ \\
\hline \multirow{2}{*}{ Mother's age groups } & $30-40$ & 20 & 66.7 & 21 & 70 \\
\hline & $\geq 41$ & 10 & 33.3 & 9 & 30 \\
\hline \multirow{3}{*}{ Mother's education } & Grades 1-11 & 8 & 26.7 & 2 & 6.7 \\
\hline & $\begin{array}{l}\text { High school } \\
\text { graduate }\end{array}$ & 15 & 50 & 24 & 80 \\
\hline & Academic & 7 & 23.3 & 4 & 13.3 \\
\hline \multirow{4}{*}{ Mother's job } & Housewife & 23 & 76.7 & 27 & 90 \\
\hline & Employee & 7 & 23.3 & 1 & 3.3 \\
\hline & Others & 0 & 0 & 1 & 3.3 \\
\hline & Retired & 0 & 0 & 1 & 3.3 \\
\hline \multirow{3}{*}{ Father's job } & Grades 1-11 & 1 & 3.3 & 2 & 6.7 \\
\hline & High school graduate & 16 & 53.3 & 6 & 20 \\
\hline & Academic & 13 & 43.3 & 22 & 73.3 \\
\hline \multirow{3}{*}{ The economic situation } & average & 24 & 80 & 22 & 73.3 \\
\hline & good & 6 & 20 & 7 & 23.3 \\
\hline & The best & 0 & 0 & 1 & 3.3 \\
\hline \multirow{2}{*}{ Number of households } & 3 & 3 & 10 & 2 & 6.7 \\
\hline & $4 \geq$ & 27 & 90 & 28 & 93.3 \\
\hline \multirow{4}{*}{$\begin{array}{l}\text { Number of children per } \\
\text { household }\end{array}$} & 1 & 2 & 6.7 & 2 & 6.7 \\
\hline & 2 & 21 & 70 & 20 & 66.7 \\
\hline & 3 & 7 & 23.3 & 6 & 23.3 \\
\hline & 4 & 0 & 0 & 1 & 3.3 \\
\hline \multirow{2}{*}{ The gender of the children } & Just girl & 10 & 33.3 & 12 & 40 \\
\hline & Just boy & 20 & 66.7 & 18 & 60 \\
\hline \multirow{2}{*}{ The age of the girls } & $\leq 14$ & 16 & 53.3 & 14 & 46.7 \\
\hline & $14>$ & 14 & 46.7 & 16 & 53.3 \\
\hline \multirow{2}{*}{$\begin{array}{l}\text { Does the teen girl have an } \\
\text { older sister? }\end{array}$} & Yes & 8 & 26.7 & 4 & 13.3 \\
\hline & No & 22 & 73.3 & 26 & 86.7 \\
\hline Sign of puberty in teenage girl & Yes & 25 & 83.3 & 27 & 90 \\
\hline
\end{tabular}

Table 2. Comparison of the progression of the total score of knowledge, attitude, behaviour and constructs of the health belief model

\begin{tabular}{|l|c|c|c|c|c|}
\hline \multirow{2}{*}{} & \multicolumn{2}{|c|}{$\begin{array}{c}\text { Comparison group } \\
\text { N=30 }\end{array}$} & \multicolumn{2}{c|}{$\begin{array}{c}\text { Intervention group } \\
\text { N=30 }\end{array}$} & $\begin{array}{c}\text { Independent } \\
\text { T }\end{array}$ \\
\cline { 2 - 6 } & $\begin{array}{c}\text { SD } \\
\text { (Standard } \\
\text { deviation) }\end{array}$ & Mean & $\begin{array}{c}\text { SD } \\
\text { (Standard } \\
\text { deviation) }\end{array}$ & Mean & $\begin{array}{c}\text { Test } \\
P \text {-value }\end{array}$ \\
\hline Knowledge & 8.45 & 1 & 22.18 & 11 & 0.027 \\
\hline Attitude & 1.96 & 0 & 17.61 & 10.08 & 0.004 \\
\hline Performance & 5.51 & 0.83 & 23.21 & 16.94 & 0.001 \\
\hline Perceived susceptibility & 8.78 & 2.83 & 21.39 & 11.67 & 0.043 \\
\hline Perceived severity & 7.48 & -0.98 & 8.80 & 3.20 & 0.053 \\
\hline Perceived benefits & 7.15 & 1.17 & 8.30 & 0 & 0.562 \\
\hline Perceived barriers & 3.62 & -2 & 12.75 & 3.33 & 0.035 \\
\hline Self-efficacy & 3.62 & 1.50 & 11.53 & 5.83 & 0.056 \\
\hline $\begin{array}{l}\text { Guideline construct for } \\
\text { action }\end{array}$ & 7.16 & 0.67 & 10.95 & 1.83 & 0.30 \\
\hline
\end{tabular}

the control group did not change during the study, the mean knowledge scores among participants in the intervention group increased from $80.3(\mathrm{SD}=25.1)$ at the baseline to $91.3(\mathrm{SD}=8.1)$ after the intervention $(p \leq 0.05)$. The attitude score was also improved from $59.3(\mathrm{SD}=21.0)$ at baseline to $69.4(\mathrm{SD}=9.4)$ after the intervention $(p \leq 0.05)$. The behaviour score was $51.6(\mathrm{SD}=21.3)$ in the intervention group at baseline and increased to $68.6(\mathrm{SD}=19.5)$ after the intervention $(p \leq 0.05)$.

Two of the HBM constructs scores were also improved in the intervention group during the study. The perceived susceptibility score was increased from $74.1(\mathrm{SD}=19.4)$ at baseline to $85.8(\mathrm{SD}=11.97)$ after the intervention $(p \leq 0.05)$. The perceived barriers score was also improved from $58.8(\mathrm{SD}=17.5)$ at baseline to $62.1(\mathrm{SD}=17.5)$ after the intervention $(p \leq 0.05)$. Other constructs did not change significantly in both the intervention and control groups after the intervention.

\section{Discussion}

This study aimed to investigate the effects of a sex education program for mothers of adolescent girls based on the HBM on mothers' knowledge, attitude, and behaviour. The results showed that our educational intervention was effective in improving knowledge, attitude, behaviour, and some HBM constructs among mothers.

Our study showed that the knowledge increased significantly in the intervention group. In a study conducted by Kazemi to assess the relationship between family variables (income, parents' education level, information rate, occupation and source of information found) with knowledge of secondary school students towards puberty health, mothers' knowledge has been identified as the most promising predictor of adolescents' knowledge on puberty health [25]. Anooshe et al. showed in their study that mothers and health educators had low awareness and inadequate understanding of puberty and its issues [17]. Mobredi et al. showed in their study that the sexual education program influenced the knowledge and attitude of pre-schoolers' mothers [26].

Studies in Iran on parents' attitudes and views about adolescent sexual education have shown various results. While Vaghari Zamharir has stated that parents are in favour of educating their teens, Forouzi Azizzadeh, Nahidi and Nair have reported negative attitudes of parents towards these kinds of education [20,27-29].

A study by Hartmann [30] in Mexican mother, their adolescents, and sex educators showed that in their school-based educational intervention to reduce the risk of unsafe sexual behaviours, mothers tended to communicate with their adolescents for prevention messages; however, for various reasons such as lack of awareness, lack of self- 

behaviour

efficacy, and lack of a good feeling in paying to gender issues, they felt limitations and tended to bring the entire training to the school.

In our study, the behaviour was significantly improved three months after the intervention. In the study of Liavshina GK among parents of Russian children aged 2-11 years to assess their knowledge of psychosocial and sexual development with regard to their children's sexual educations, authors found that $54 \%$ of the parents never read a book about sex education issues; and $42 \%$ of those who had some information did not use it. One third of the parents believed that sexual education was not their responsibility, and less than half of them had never talked to their children about sexual behaviour [31].

There was a significant increase in the perceived susceptibility score in the intervention group after the educational intervention. However, there was no significant difference in the perceived benefits in the intervention group after the intervention. The mean perceived barriers score increased significantly after the intervention in the intervention group. Several studies have shown that the perceived barriers are strong predictors of health promoting behaviours [32,33]. Providing useful solutions to overcome these perceived barriers can help mothers to carry out sexual education.

Generally, the results of this study show that the mean scores of knowledge, attitude, and behaviour and the perceived susceptibility and perceived barriers have significantly changed in the intervention group compared with the control group, 3 months after the educational intervention. The study shows positive effects of educational program designed based on the HBM. In a study conducted in parents by Brock and Beazley [34] aiming at using the HBM to measure the participation of adolescents' families in sexual education, results showed that perceived barriers were highly correlated with the lack of families' involvement in sexual health education; and perceived barriers and perceived selfefficacy were the most important predictors in differentiating parents' involvement in sexual health education.

\section{Strength and limitations of the study}

To our knowledge, this is one of the few studies conducted on the issue in Iran. We used rigor methods in conducting this study; however, there were some limitations. Since it was a sensitive issue, we considered recommended points in conducting sensitive issues in our study. Mothers were reluctant to participate in the study; so, we tried to persuade them and assure them of confidentiality and anonymity. We need to examine ways to find out whether mothers communicated with their daughters on sexual issues and used our taught. Mothers in our study needed to know how they can discuss sexual issues with their daughters. Further qualitative studies can shed more light on mothers' perceptions and perceived barriers in this regard. This study evaluated a sexual education program for girls. Similar studies to improve communication between parents with boys is worthy. Moreover, modifying and extending the study to schools can make a broader safe environment for adolescents to receive proper sexual information.

\section{Conclusions}

Our educational intervention was effective in improving knowledge, attitude, behaviour, and some Health Belief Model constructs among mothers. Given the large number of adolescent girls in Iran, cultural sensitivities, and lack of standard sexual education, this intervention deserves consideration for implementation.

\section{References}

1. World Health Organization (2018) Adolescent Health. Available at: http://www.who int/topics/adolescent_health/en/.
2. World Health Organization (2017) World Health Statistics. pp. 149-158. Available at: www.who.int/gho/publications/world_health_statistics/2015/en/.

3. World Health Organization (2017) Adolescent health. Adolescents: health risks and solutions. Available at: www.who.int/mediacentre/factsheets/fs345/en/

4. Iran Statistics center (2018) Selection of the results of general census of population and housing 2004. Islamic Republic of Iran Statistics Center. Available at: https://www. amar.org.ir/Portals/0/News/1396/chnsanvms95.pdf.

5. Lackovic-Grgin K, Dekovic M, Opacic G (1994) Pubertal status, interaction with significant others, and self-esteem of adolescent girls. Adolescence 29: 691. [Crossref]

6. Pietilä A-M, Hentinen M, Myhrman A (1995) The health behavior of northern Finnish men in adolescence and adulthood. Int J Nurs Stud 32: 325-338. [Crossref]

7. Ybarra ML, Emenyonu N, Nansera D, Kiwanuka J, Bangsberg DR (2008) Health information seeking among Mbararan adolescents: results from the Uganda Media and You survey. Health Educ Res 23: 249-258. [Crossref]

8. Dempsey AF, Singer DD, Clark SJ, Davis MM (2009) Adolescent preventive health care: what do parents want? J Pediatr 155: 689-694. [Crossref]

9. Parsa M (1993) Psychology, child and adolescent development. Sixth Edition, Besat, Tehran 214-249. [In Persian]

10. World Health Organization (2017) Women health. Available at: www.who.int/topics womens health/en/.

11. World Health Organization. Women health (2013) Fact sheet on women's health Available at: www.who.int/mediacentre/factsheets/fs334/en/.

12. Parvizi S, Ahmadi F (2007) Adolescence Health and Friendships: A Qualitative study Feyz 10: 46-51. [In Persian]

13. Booth ML, Bernard D, Quine S, Kang MS, Usherwood T, et al. (2004) Access to health care among Australian adolescents' young people's perspectives and their sociodemographic distribution. J Adolesc Health 34: 97-103. [Crossref]

14. Nwagwu WE (2007) The Internet as a source of reproductive health information among adolescent girls in an urban city in Nigeria. BMC Public Health 7: 354. [Crossref]

15. Ackard DM, Neumark-Sztainer D (2001) Health care information sources for adolescents: age and gender differences on use, concerns, and needs. $J$ Adolesc Health 29: 170-176. [Crossref]

16. Ahmadi F, Anoosheh M, Vaismoradi M, Safdari MT (2009) The experience of puberty in adolescent boys: an Iranian perspective. Int Nurs Rev 56: 257-263. [Crossref]

17. Anoosheh M, Niknami S, Tavakoli R, Faghihzadeh S (2003) Preliminary Study of Puberty Education in Adolescent Girls: A Qualitative Research. IJPCP 9: 64-70. [In Persian]

18. Mirzaii Nagmabadi Kh, Babazadeh R, Shariati M, Mousavi A (2014) Iranian Adolescent Girls and Sexual and Reproductive Health Information and Services: A Qualitative Study. The Iranian Journal of Obstetrics, Gynecology and Infertility 17: 9-18. [In Persian]

19. Holman A (2014) How adolescents perceive their parents' communication about sex: Toward reducing adolescent sexual risk: University of Nebraska; 2014.

20. Nair M, Leena M, Paul MK, Pillai HV, Babu G, et al. (2012) Attitude of parents and teachers towards adolescent reproductive and sexual health education. Indian J Pediatr 79: 60-63. [Crossref]

21. Mohajer N, Bessarab D, Earnest J (2009) There should be more help out here!: A qualitative study of the needs of Aboriginal adolescents in rural Australia. Rural and remote health 9: 1-11. [Crossref]

22. Mohammadi N, Rafieefar SH (2005) Health education curriculum. Vol 3. Fourth Edition, Mehrvash, Tehran: 293-312. [In Persian]

23. Safari M, Shojaeezadeh D, Ghofranipoor F, Haydarniya A, Pakpoorhajiagha A (2012) Theories, models and methods of health education and health promotion. Second edition Department of Communications and Health Education. Tehran: 53-57. [In Persian]

24. Rosenstock LM, Strecher VJ, Becker MH (1988) Social learning theory and the Health Belief Model. Health Educ Q175-183. [Crossref]

25. Kazemi Z (2012) The Effect of Family Variables on Information Rate of Guidance School Female Students about Maturity Health. J Famil Res 8: 319-335.

26. Mobredi K, Hasanpoor-Azghady S-B, Azin S-A, Haghani H, Amiri Farahani L (2018) Effect of the Sexual Education Program on the Knowledge and Attitude of Preschoolers' Mothers. Journal of Clinical \& Diagnostic Research 12: 6.

27. Vaghari Zemehrir Z, Hejazi Z, Abiri S, Saedi Rezvani M (2015) The attitudes and actions of parents in sex education of children. Family and sex education conference in 1394. [In Persian] 
Mostofi N (2018) Effectiveness of a sex education program for mothers of adolescent girls based on Health Belief Model on mothers' knowledge, attitude, and behaviour

28. Forozi-Azizzadeh M, Mohammad-Alizadeh S (2007) Attitude and opinion of parents about sex education of adolescents and its contents in kerman. SSU Journals 15: 93 99. [In Persian]

29. Nahidi F (2010) Parents and teachers' view on appropriate time and method for female reproductive health education. J Gorgan Univ Med Sci 12: 84-90.

30. Hartmann KE (2012) Perspectives of Mexican mothers, adolescents, and sex educators on school-based sex education programs in the United States: Illonois state university; 2012.

31. Liavshina G (2001) Parents' participation in sex education of children. "Problemy sotsial'noi gigieny, zdravookhraneniia i istorii meditsiny/NII sotsial'noi gigieny, ekonomiki i upravleniia zdravookhraneniem im NA Semashko RAMN; AO" Assotsiatsiia'Meditsinskaia literatura". 22-24.
32. Hallberg U, Camling E, Zickert I, Robertson A, Berggren U (2008) Dental appointment no-shows: why do some parents fail to take their children to the dentist? Int J Paediatr Dent 18: 27-34. [Crossref]

33. Karimy M, Shamsi M, ArabanM, Gholamnia Z, Kasmai P (2012) Pap Smear Test Structures for Measuring Health Belief Model and Factors Affecting Women in Urban Centers Covered Zarandieh. Qom University of Medical Sciences Journal 6: 52-59. [In Persian]

34. Brock GC, Beazley RP (1995) Using the Health Belief Model to Explain Parents Participation in Adolescents' At-Home Sexuality Education Activities. J Sch Health 65: 124-128.

Copyright: $@ 2018$ Mostofi N. This is an open-access article distributed under the terms of the Creative Commons Attribution License, which permits unrestricted use, distribution, and reproduction in any medium, provided the original author and source are credited. 